Supporting Information

\title{
Quantifying Ligand Exchange Reactions at CdSe Nanocrystal Surfaces
}

\author{
Robin R. Knauf, J. Christian Lennox, and Jillian L. Dempsey* \\ Department of Chemistry, University of North Carolina, Chapel Hill, NC 27599-3290 \\ *Correspondence to: dempseyj@email.unc.edu
}

\begin{abstract}
Table of Contents

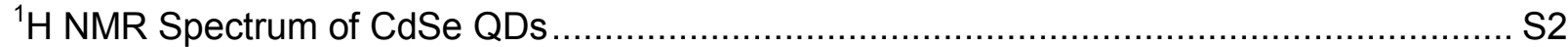

Absorbance and Photoluminescence Spectra of CdSe QDs ........................................ S2

Steady-State and Time-Resolved Emission Spectra of CdSe QDs During Purification.......... S3

${ }^{1} \mathrm{H}$ NMR Spectrum of CdSe QDs and Ferrocene ......................................................... 3

Integration of the $600 \mathrm{MHz}{ }^{1} \mathrm{H}$ NMR Spectrum of CdSe QDs and UDA ............................. S4

$K_{\text {eq }}$ and Ligand Exchange Ratio for CdSe Titrations with UDA ...................................... S4

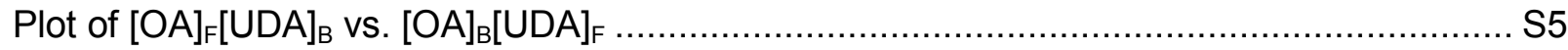

${ }^{1} \mathrm{H}$ NMR Spectrum of CdSe QDs and UDA Upon Dilution ............................................. S5

Addition of Free OA to the End of a CdSe Titration with UDA ........................................ S6

Variable Temperature ${ }^{1} \mathrm{H}$ NMR Spectra of CdSe QDs and UDA ................................... S6

${ }^{1} \mathrm{H}$ NMR Spectrum of the Addition of Free OA to UDPA-capped CdSe QDs........................ S7

${ }^{1} \mathrm{H}$ NMR Spectrum of the Addition of Free OPA to UDPA-capped CdSe QDs ..................... S7

Absorption and PL Spectra of CdSe QDs titrated with 1:1 and 1:2 UDPA:Base ................. S8

Absorbance Spectrum of CdSe QDs with Excess UDPA After 2 Days .............................. S9

Ligand Exchange Ratios Obtained from the Titration of CdSe with UDT ........................... S9

${ }^{1} \mathrm{H}$ NMR Spectrum of the Addition of Free OA to UDT-capped CdSe QDs ....................... S10

Absorbance and PL Spectra of CdSe Titrated with DDT ......................................... S10

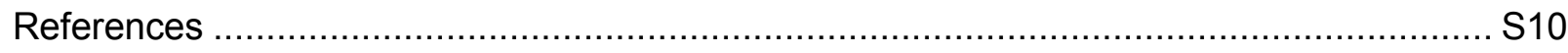




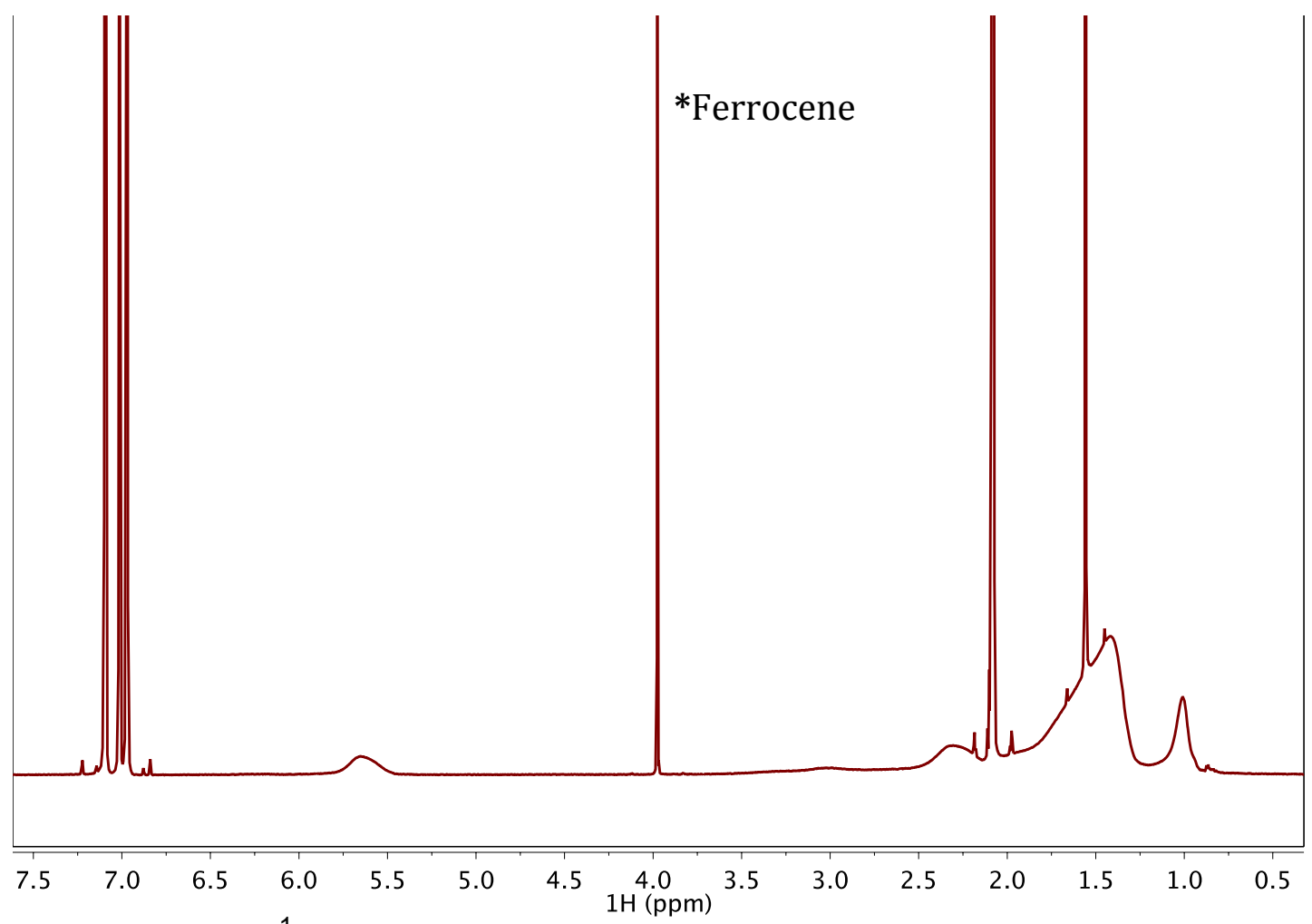

Figure S1: $600 \mathrm{MHz}{ }^{1} \mathrm{H}$ NMR spectrum of CdSe QDs in toluene- $d_{8}$. Peaks at 7.09, 7.01, 6.97 , and $2.08 \mathrm{ppm}$ correspond to residual toluene solvent signals. The singlet peak at $3.98 \mathrm{ppm}$ corresponds to the ferrocene standard. The singlet at $1.56 \mathrm{ppm}$ is due to residual water in the NMR solvent.

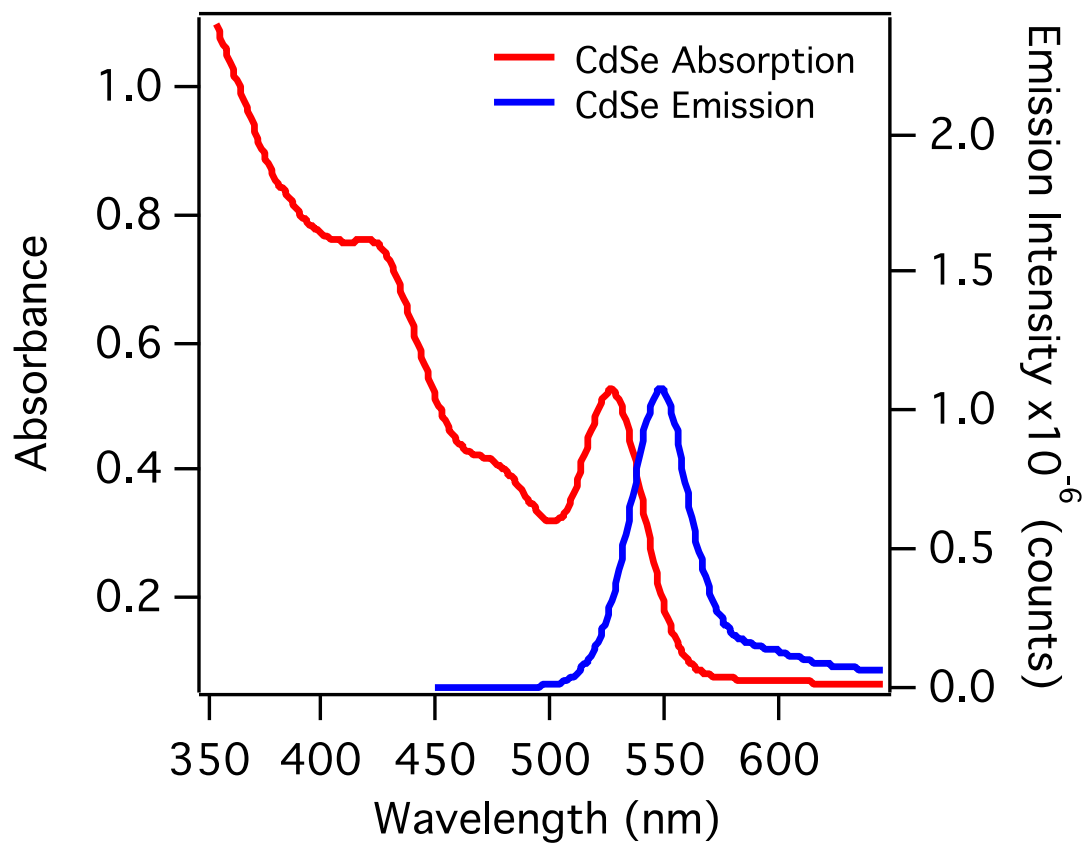

Figure S2: Absorbance and photoluminescence spectra of CdSe QDs in toluene after purification. Emission spectrum collected at $425 \mathrm{~nm}$ excitation. 

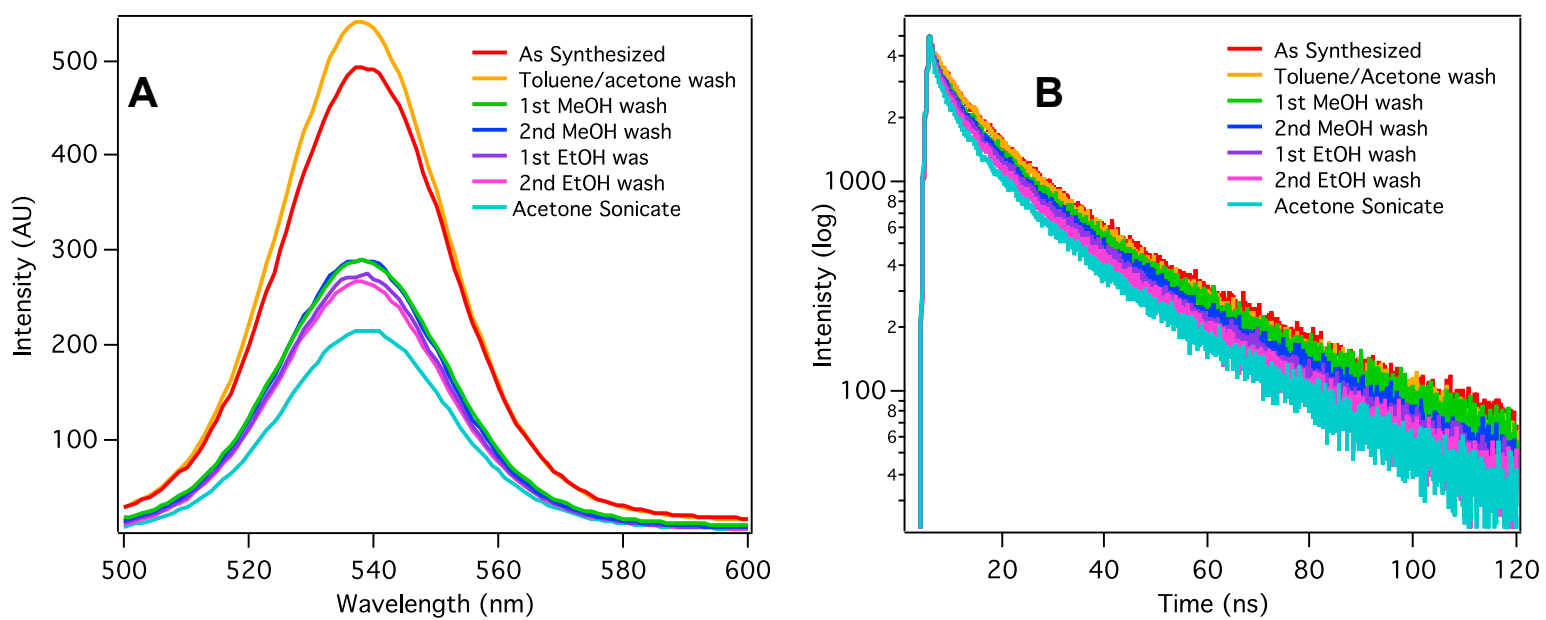

Figure S3: (A) Steady-state photoluminescence spectrum of $2.1 \mu \mathrm{M}$ CdSe QDs in toluene after various purification steps (425 nm excitation). (B) Time-resolved photoluminescence spectrum of $2.1 \mu \mathrm{M}$ CdSe QDs at 540nm in toluene after various purification steps (444 $\mathrm{nm}$ excitation).

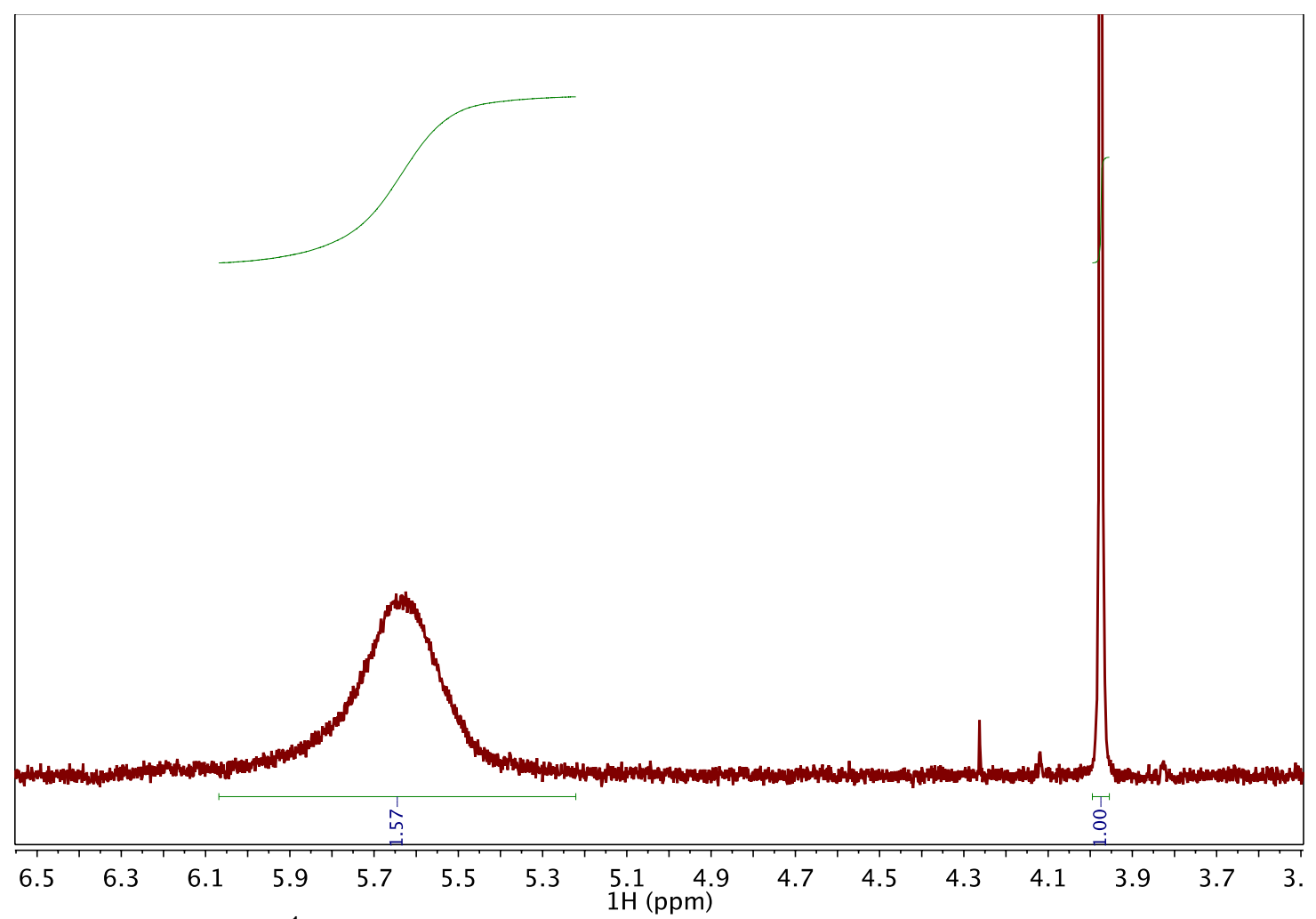

Figure S4: $600 \mathrm{MHz}{ }^{1} \mathrm{H}$ NMR spectrum of $111 \mu \mathrm{M}$ CdSe QDs (5.64 ppm) and $493 \mu \mathrm{M}$ ferrocene $(3.97 \mathrm{ppm})$ in toluene- $d_{8}$. A ligand density of $1.2 \mathrm{OA} / \mathrm{nm}^{2}$ is determined from the integrals of these peaks. 


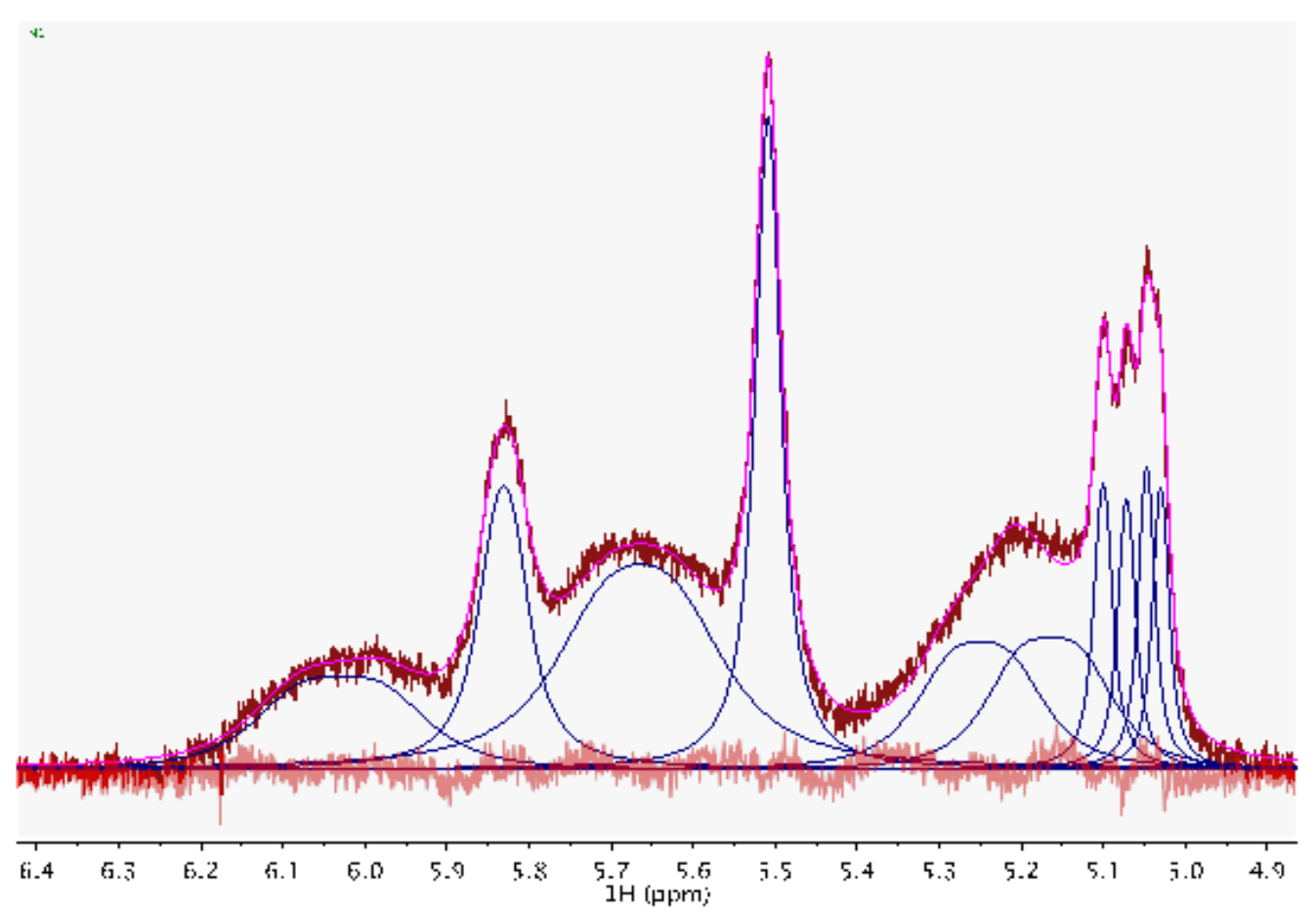

Figure S5: Multi-peak fitting of the $600 \mathrm{MHz}{ }^{1} \mathrm{H}$ NMR spectrum of CdSe QDs and UDA in toluene- $d_{8}$. The maroon trace is the sample NMR spectrum, the magenta trace is the fit, and the red trace is the fit residual.

\begin{tabular}{|lcc|}
\hline$[U D A]$ added $(M)$ & $\boldsymbol{K}_{\text {eq }}$ & ${ }_{\text {[OA }}$ : $:[U D A]_{B}$ \\
\hline $\mathbf{0 . 0 0 2}$ & 0.82 & $1.1: 1$ \\
\hline $\mathbf{0 . 0 0 3}$ & 0.89 & $0.87: 1$ \\
\hline $\mathbf{0 . 0 0 4}$ & 0.77 & $1.03: 1$ \\
\hline $\mathbf{0 . 0 0 6}$ & 0.78 & $0.92: 1$ \\
\hline $\mathbf{0 . 0 1}$ & 0.83 & $0.96: 1$ \\
\hline $\mathbf{0 . 0 1 2}$ & 0.88 & $0.92: 1$ \\
\hline $\mathbf{0 . 0 1 5}$ & 0.88 & $1.1: 1$ \\
\hline $\mathbf{0 . 0 2 5}$ & 0.89 & $1.02: 1$ \\
\hline Diluted to 0.008 & 0.86 & $0.89: 1$ \\
\hline OA added (0.01M) & 0.80 & - \\
\hline Average & $\mathbf{0 . 8 4} \pm \mathbf{0 . 0 5}$ & $\mathbf{0 . 9 8}(\mathbf{\pm 0 . 0 9 )}: \mathbf{1}$ \\
\hline
\end{tabular}

Table S1: $K_{\text {eq }}$ and ligand exchange ratio obtained for different additions of UDA to a sample of CdSe QDs. The standard deviation for $K_{\text {eq }}$ is 0.05 . 


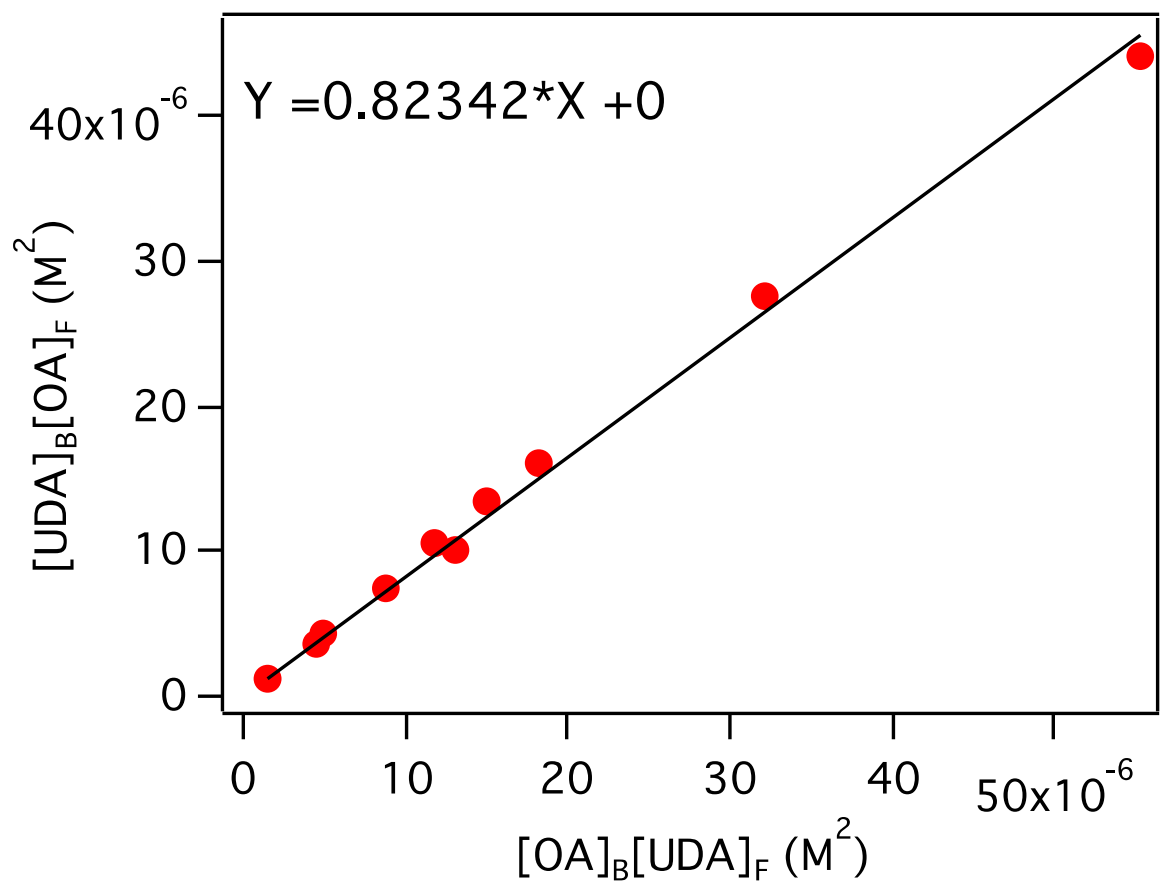

Figure S6: Plot of $[O A]_{F}[U D A]_{B}$ vs. $[O A]_{B}[U D A]_{F}$. From the expression for $K_{\text {eq }}\left(K_{e q}=\right.$ $\left.\frac{[O A]_{F}\left[X^{-}\right]_{B}}{[\text { oleate }]_{B}[X H]_{F}}\right)$, the slope of this plot can be used to determine an average $K_{\text {eq }}$ for the ligand exchange between OA and UDA.

\section{— End of UDA Titration \\ -Diluted 1:3 (Normalized)}

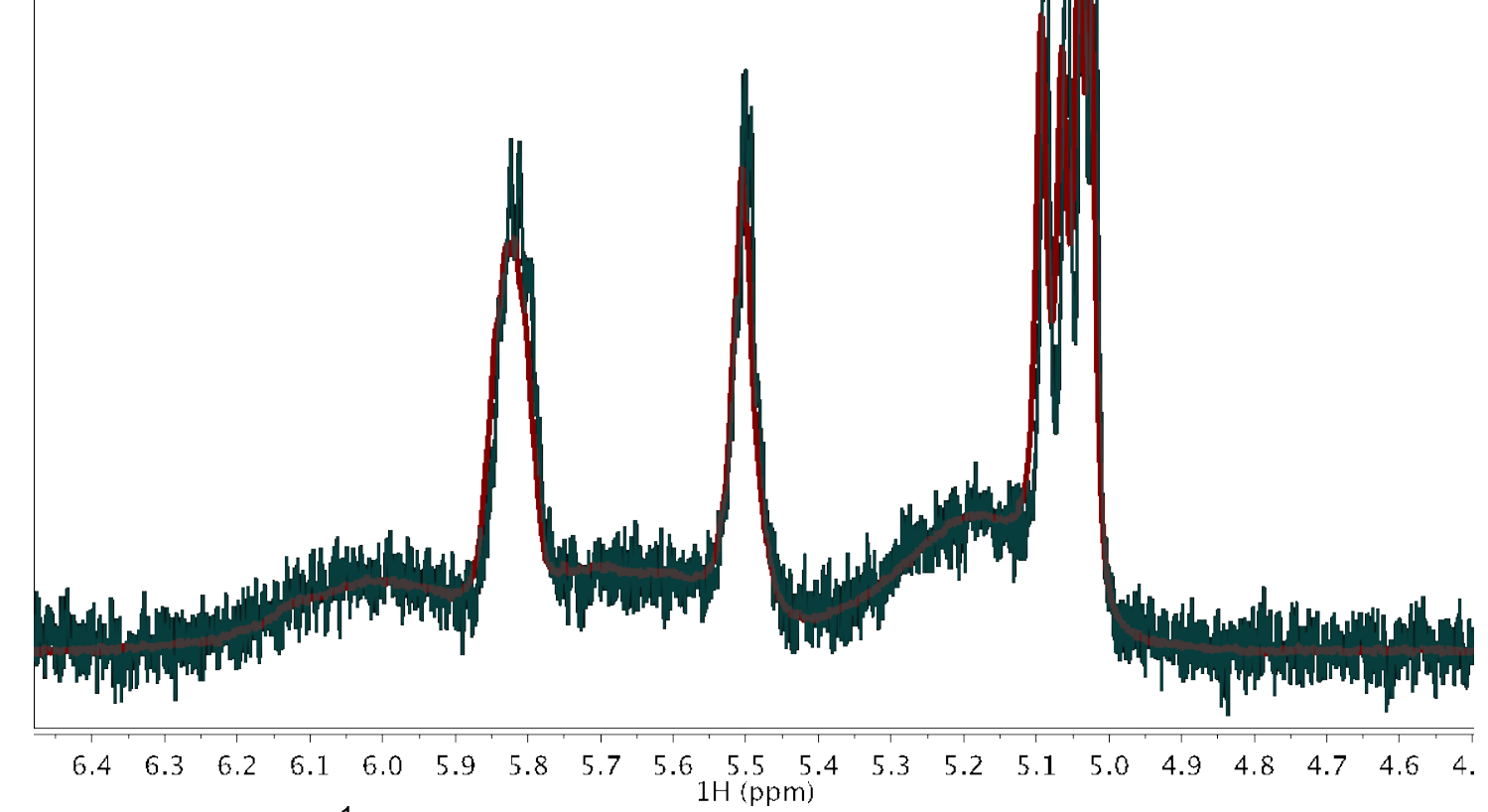

Figure S7: $600 \mathrm{MHz}{ }^{1} \mathrm{H}$ NMR spectrum of $100 \mu \mathrm{M}$ CdSe QDs and $0.012 \mathrm{M}$ UDA in toluene- $d_{8}$ before (maroon) and after (teal, normalized) dilution by a factor of 3 . 


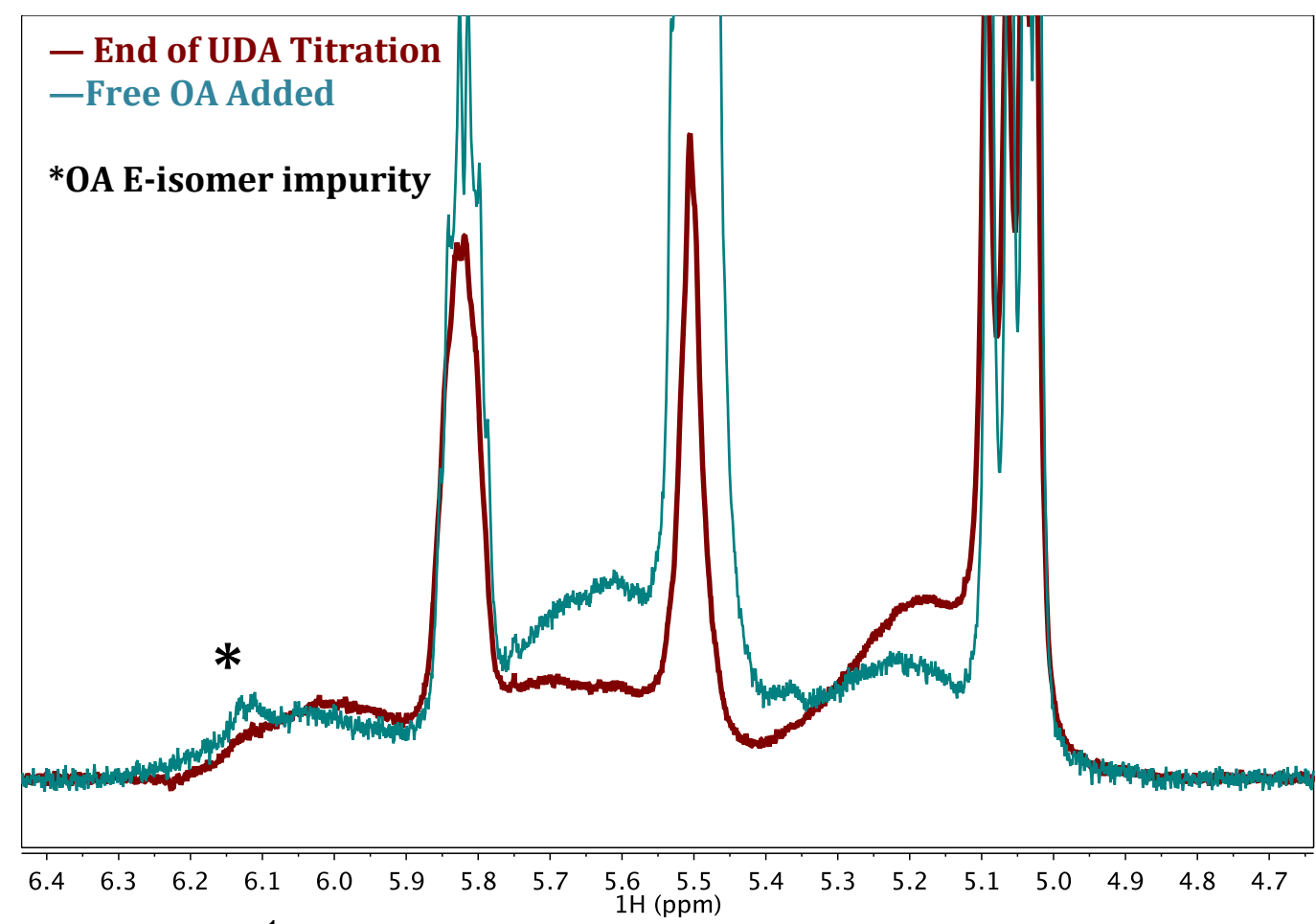

Figure S8: $600 \mathrm{MHz}{ }^{1} \mathrm{H}$ NMR spectrum of $100 \mu \mathrm{M}$ CdSe QDs and $0.012 \mathrm{M}$ UDA in toluene- $\mathrm{d}_{8}$ before (maroon) and after (teal) the addition of $0.010 \mathrm{M}$ free oleic acid. The stared peak indicates the E-isomer of OA that is present in lab grade OA.

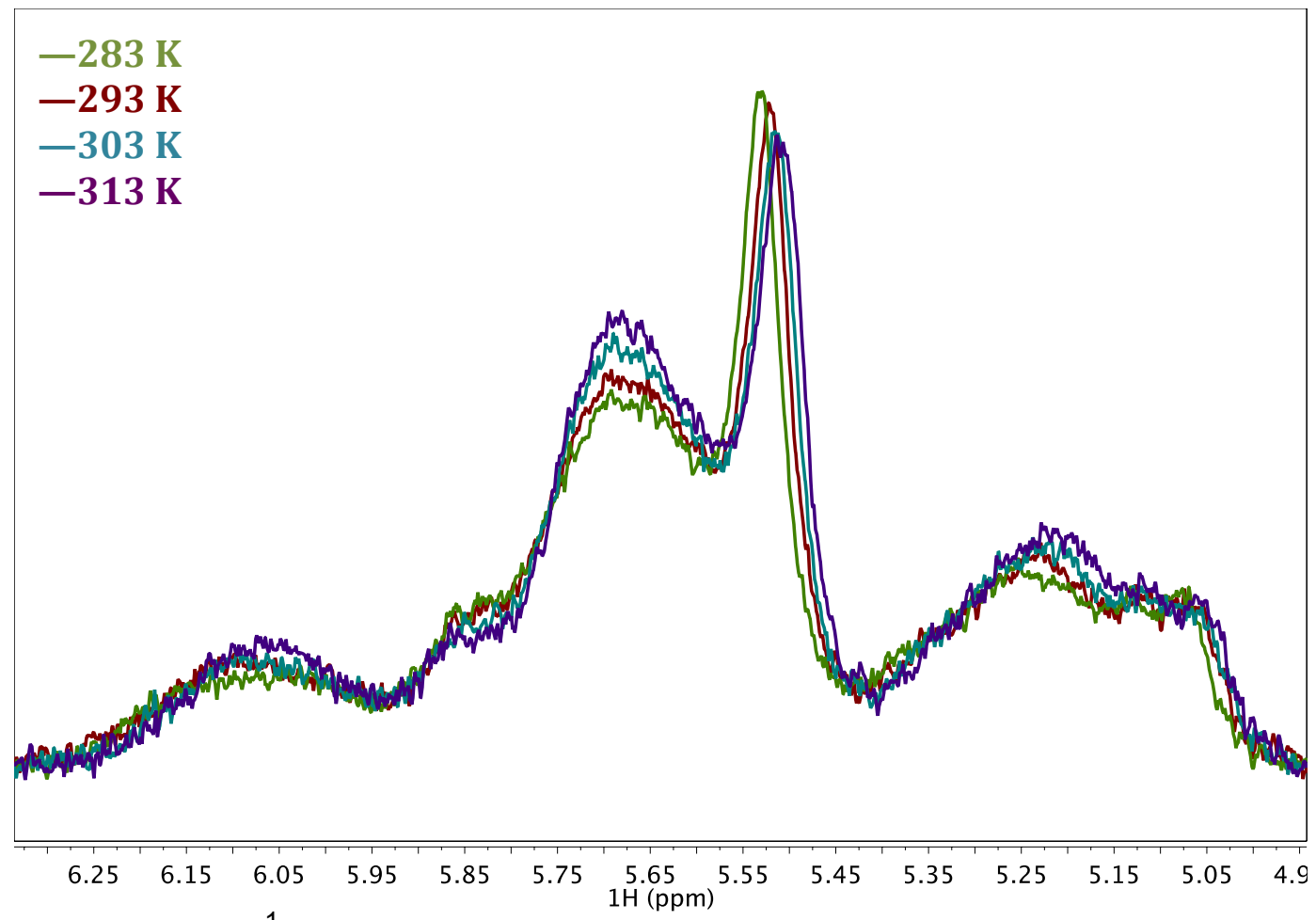

Figure S9: $500 \mathrm{MHz}{ }^{1} \mathrm{H}$ NMR spectrum of $1.5 \mathrm{mM}$ UDA and $100 \mu \mathrm{M} Q \mathrm{QD}$ at temperatures ranging from $283 \mathrm{~K}$ to $313 \mathrm{~K}$. 


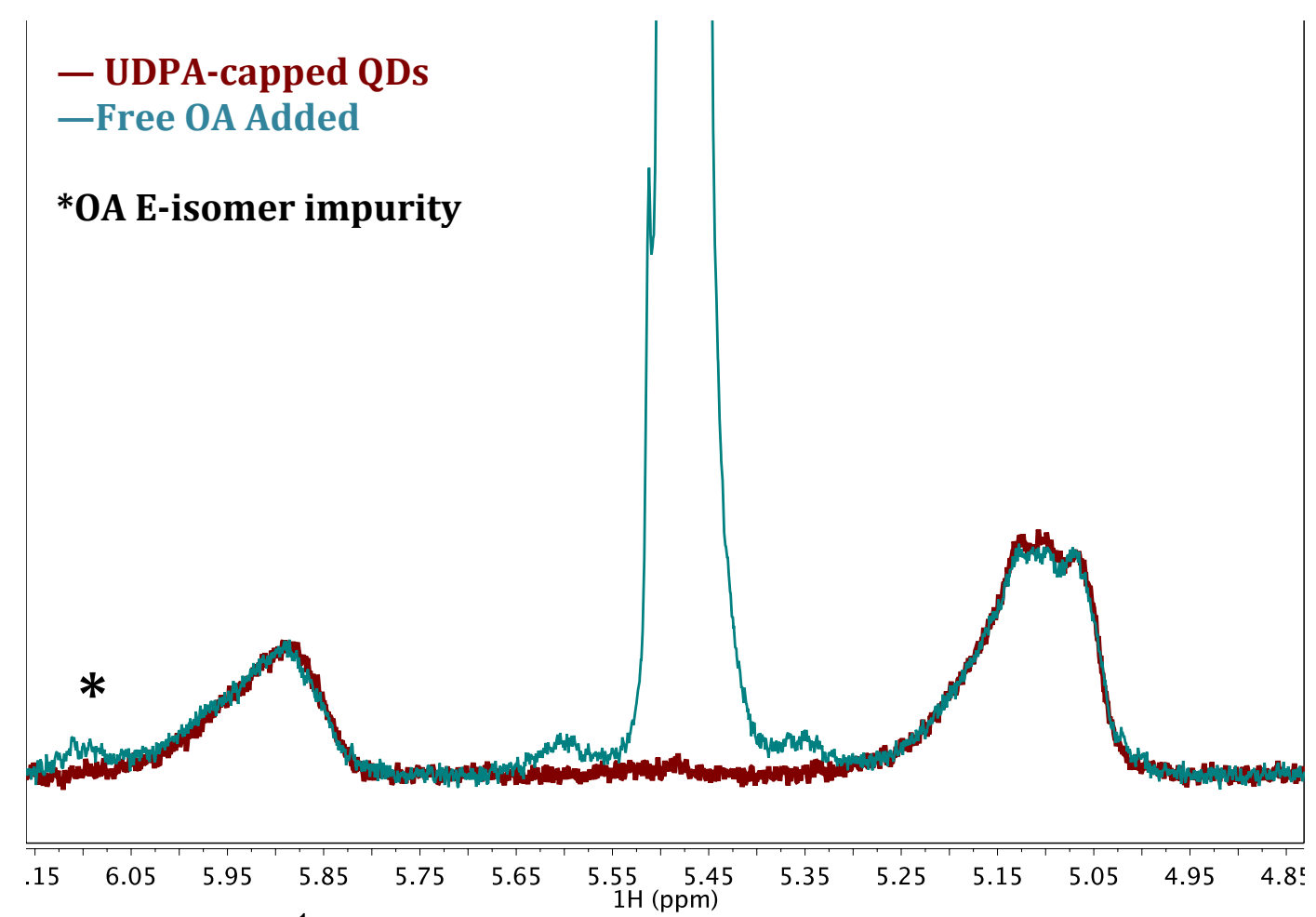

Figure S10: $600 \mathrm{MHz}{ }^{1} \mathrm{H}$ NMR spectrum of CdSe QDs capped with UDPA before (maroon) and after (teal) the addition of free OA. The starred peak indicates the Eisomer of $\mathrm{OA}$ that is present in lab grade OA.

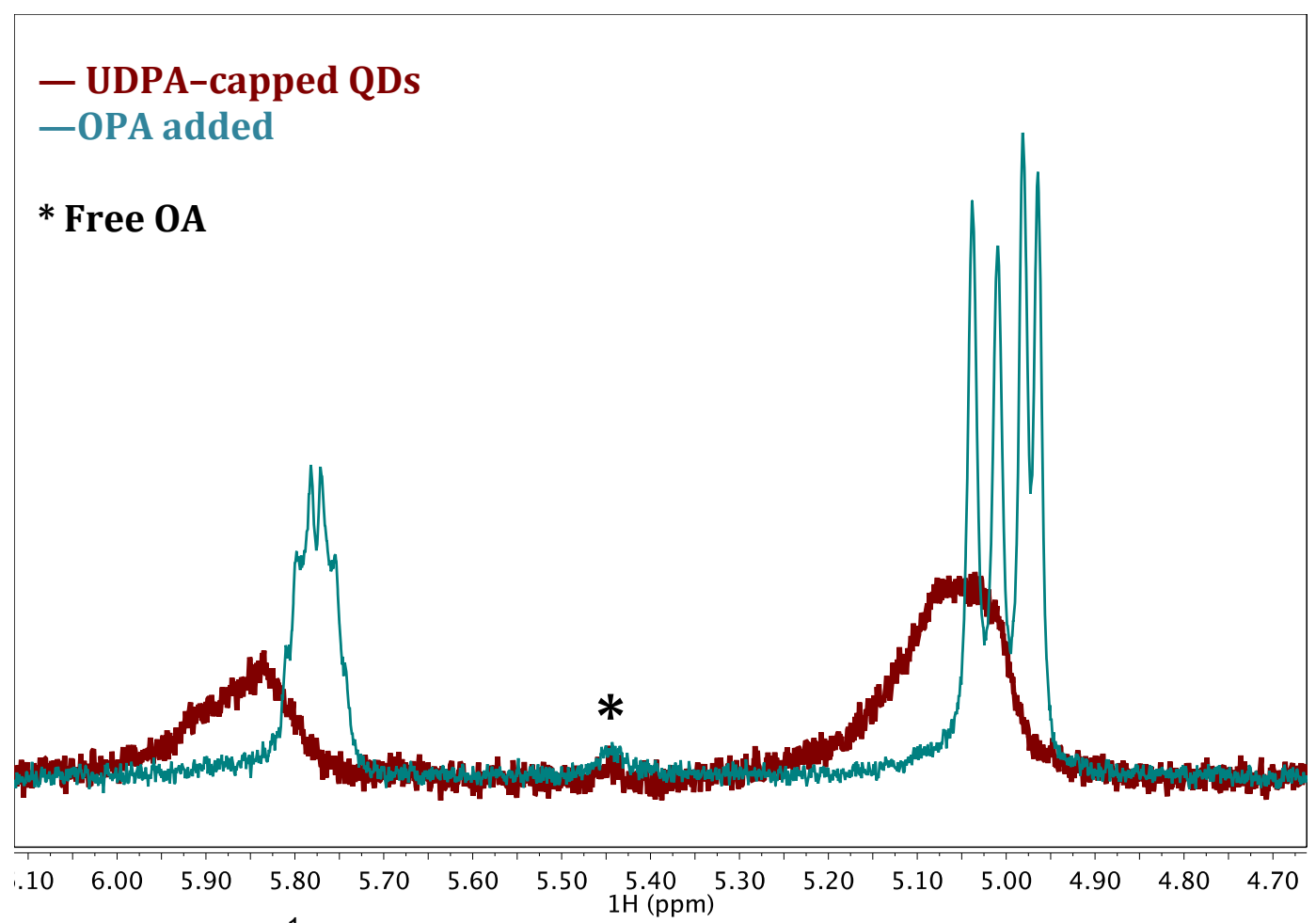

Figure S11: $600 \mathrm{MHz}{ }^{1} \mathrm{H}$ NMR spectrum of CdSe QDs capped with UDPA before (maroon) and after (teal) the addition of free octylphosphonic acid (OPA). The starred peak indicates residual free OA. 

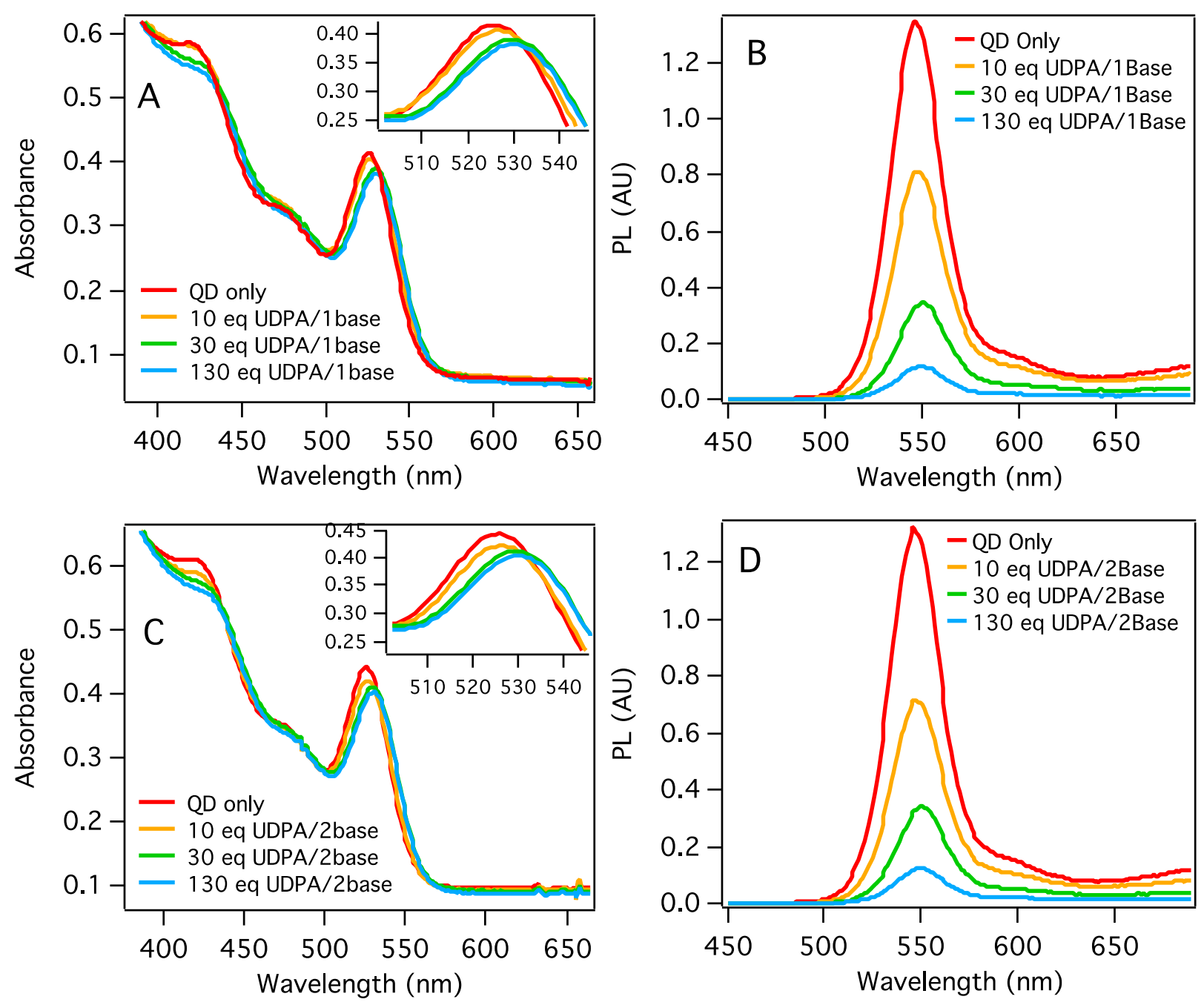

Figure S12: (A) Absorption spectrum of $2.3 \mu \mathrm{M}$ CdSe QDs in toluene titrated with UDPA and 1 equivalent N,N-diisopropylethylamine. (B) Steady-state PL spectrum (425 $\mathrm{nm}$ excitation) of $2.3 \mu \mathrm{M}$ CdSe QDs in toluene titrated with UDPA and 1 equivalent $\mathrm{N}, \mathrm{N}$ diisopropylethylamine. (C) Absorption spectrum of $2.3 \mu \mathrm{M}$ CdSe QDs in toluene titrated with UDPA and 2 equivalents N,N-diisopropylethylamine. (D) Steady-state PL spectrum (425 nm excitation) of $2.3 \mu \mathrm{M}$ CdSe QDs in toluene titrated with UDPA and 2 equivalents $\mathrm{N}, \mathrm{N}$-diisopropylethylamine. 


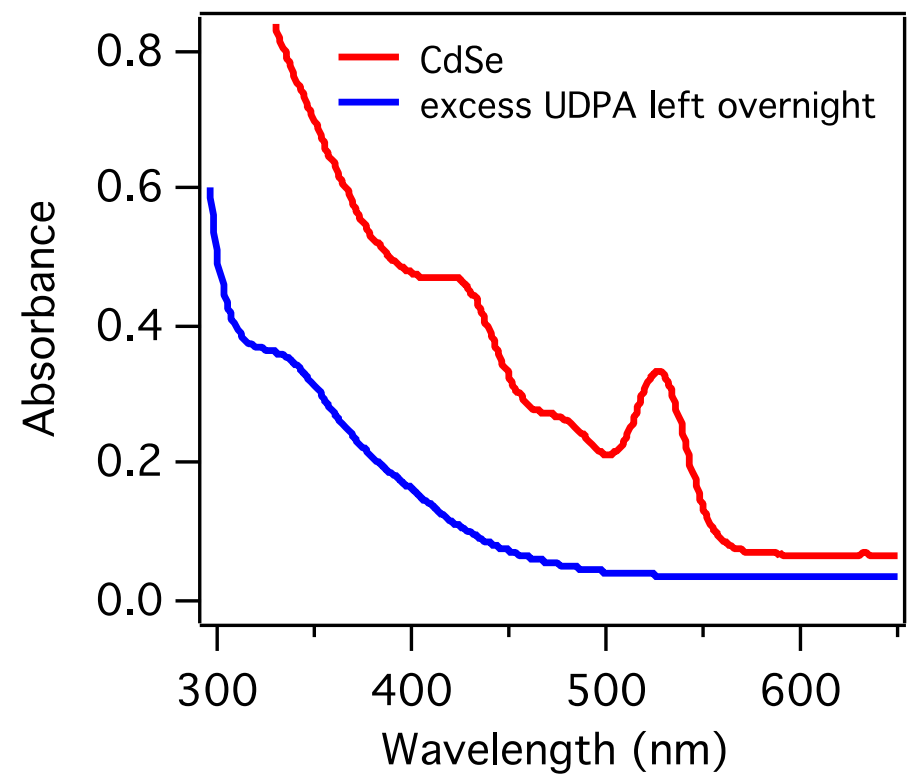

Figure S13: Absorbance of $2 \mu \mathrm{M}$ QDs CdSe QDs (red) in excess UDPA for 2 days (blue).

\begin{tabular}{|c|c|c|c|c|}
\hline $\begin{array}{c}\text { [UDT] added } \\
\text { (M) }\end{array}$ & {$[0 A]_{\mathrm{F}:}[\mathrm{UDT}]_{\mathrm{B}}$} & $\begin{array}{c}\text { OA Coverage } \\
\left(0 \mathrm{~A} / \mathrm{nm}^{2}\right)\end{array}$ & $\begin{array}{c}\text { UDT } \\
\text { Coverage } \\
\left(\mathrm{UDT} / \mathrm{nm}^{2}\right)\end{array}$ & $\begin{array}{l}\text { Total ligand } \\
\text { Coverage } \\
\text { (Ligands } / \mathrm{nm}^{2} \text { ) }\end{array}$ \\
\hline 0.0005 & $1: 2.30$ & 1.3 & 0.2 & 1.5 \\
\hline 0.001 & $1: 2.11$ & 1.2 & 0.4 & 1.6 \\
\hline 0.002 & $1: 1.89$ & 1.1 & 0.5 & 1.6 \\
\hline 0.003 & $1: 1.71$ & 1.0 & 0.6 & 1.6 \\
\hline 0.006 & $1: 1.62$ & 0.8 & 1.0 & 1.8 \\
\hline 0.008 & $1: 1.59$ & 0.6 & 1.3 & 1.9 \\
\hline
\end{tabular}

Table S2: Ligand exchange ratios and ligand coverages obtained for different additions of UDT to a sample of OA-capped CdSe QDs. 


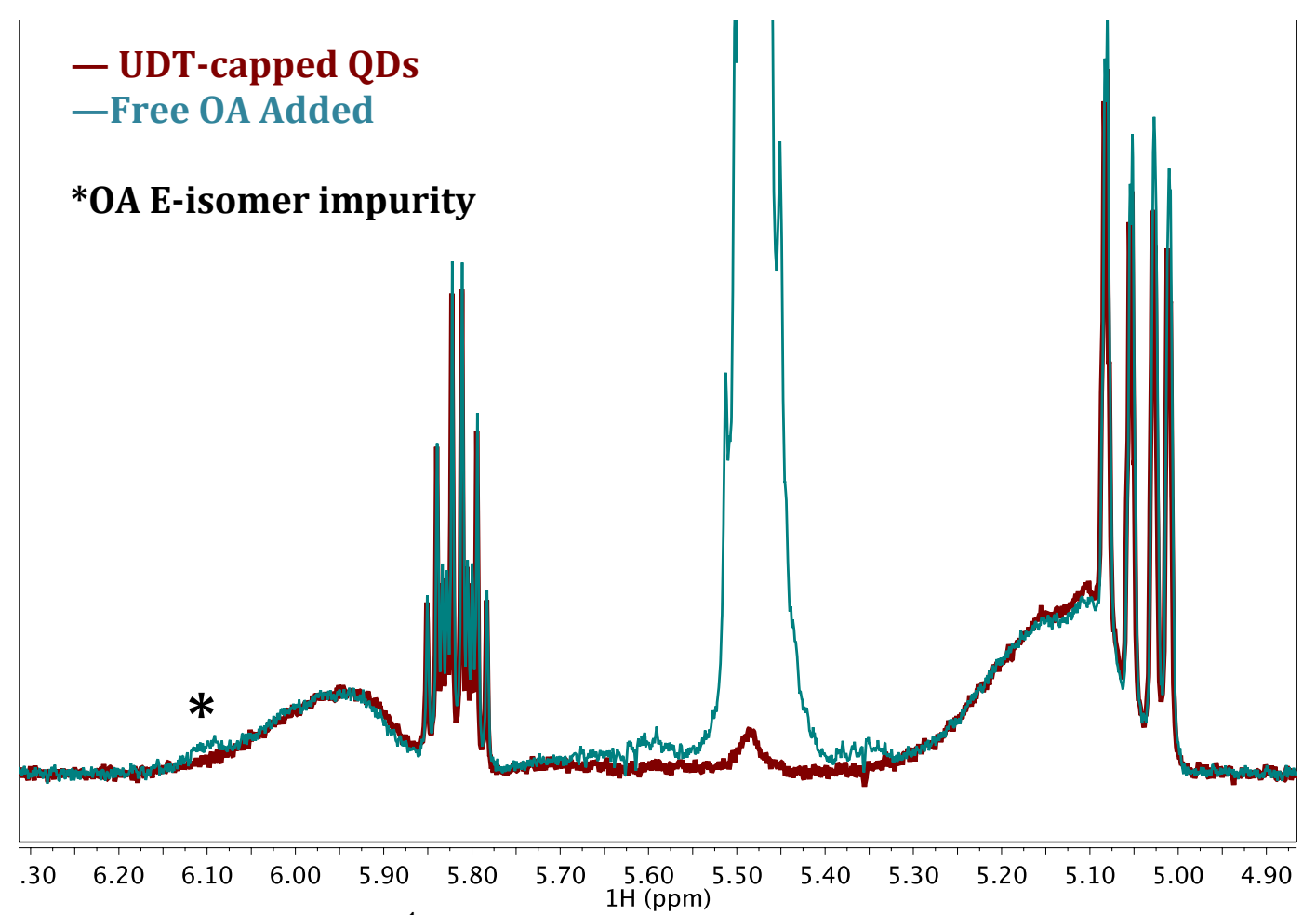

Figure S14: $600 \mathrm{MHz}{ }^{1} \mathrm{H}$ NMR spectrum of CdSe QDs capped with UDT before (maroon) and after (teal) the addition of free OA. The starred peak indicates the Eisomer of $O A$ that is present in lab grade OA.
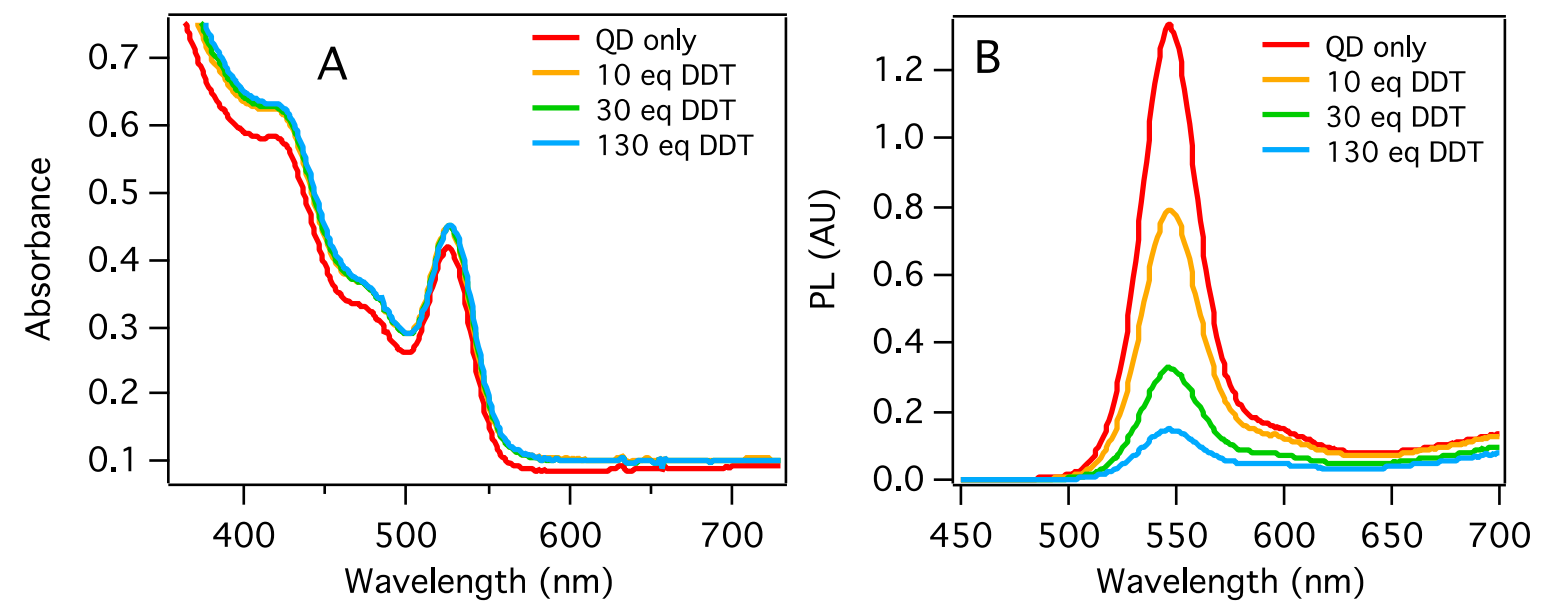

Figure S15: (A) Absorption spectrum of $2.3 \mu \mathrm{M}$ CdSe QDs in toluene titrated with dodecanethiol. (B) Steady-state PL spectrum (425 nm excitation) of $2.3 \mu \mathrm{M}$ CdSe QDs in toluene titrated with dodecanethiol.

\section{References}

1. Anderson, N. C.; Hendricks, M. P.; Choi, J. J.; Owen, J. S. Ligand Exchange and the Stoichiometry of Metal Chalcogenide Nanocrystals: Spectroscopic Observation of Facile Metal-Carboxylate Displacement and Binding J. Am. Chem. Soc. 2013, 135 (49), 1853618548. 